\title{
Core Biópsia, Tru-Cut Biópsia, Punção Lancetante ou Biópsia por Punção com Agulha Fragmentante Tecidual (Punção Fragmentante - PFrag)?
}

\section{Caro Editor,}

Por vários anos temos enfrentado um dilema semântico ao tentarmos traduzir do inglês os termos Core Biopsy ou Tru-Cut Biopsy, utilizados para expressar técnicas de obtenção de uma amostra tecidual através da utilização de agulhas especiais que seccionam um hemicilindro de lesão, permitindo avaliação histológica através desta técnica minimamente invasiva que é a punção transcutânea. O ilustre professor Nelson Porto por muitos anos tem sugerido o nome punção lancetante como uma solução para este problema. Este nome, que é amplamente aceito no Rio Grande do Sul, especialmente entre os discípulos desse brilhante e erudito professor, infelizmente não ganhou aceitação nacional e ainda vemos muitos artigos em jornais médicos publicados em língua portuguesa utilizando a inadequada denominação Core biópsia ou Tru-Cut biópsia, que não pertencem ao nosso idioma.

O termo biópsia por punção transcutânea com agulha fragmentante tecidual, que poderia ser abreviado de forma simplificada para punção fragmentante (PFrag), foi sugerido na tese de doutoramento da Dra. L. Irion como alternativa para aqueles que infelizmente não aceitaram a denominação punção lancetante proposta pelo Prof. Porto. Ao cunharmos essa denominação, levamos em consideração que o processo de obtenção da amostra para análise histológica dê-se através da utilização de agulhas pro- jetadas para atravessar a pele e recuperar um fragmento do tecido da lesão. Aqui, outra importante contribuição do Prof. Porto deve ser lembrada no momento de redigirmos nossos artigos científicos: a expressão punção percutânea é inadequada, pois o processo sempre causa ruptura da pele, ou seja, é um procedimento transcutâneo e não há possibilidade de atingir a lesão com a agulha por permeabilidade da pele, como indica o termo percutâneo. Em alguns artigos notamos a citação de agulha cortante, o que não diferencia adequadamente, pois em princípio todas as agulhas são cortantes.

Agradecemos ao Prof. Dr. Nelson Porto por seus valiosos ensinamentos e por suas sugestões na elaboração desta carta.

\section{Klaus Loureiro Irion}

Doutor em Medicina: Pneumologia; UFRGS (Consultant Radiologist Pennine Acute Hospitals, England)

\section{Luciane Dreher Irion}

MSc (Médica Patologista do Central Manchester and Manchester Children's University Hospitals NHS Trust)

\section{Bruno Hochhegger}

Médico

Programa de Pós-Graduação em Ciências Pneumológicas da Universidade Federal do Rio Grande do Sul.

Endereço para correspondência: 912 Manchester Road, Bury, England. Post code: BL98DW 